\title{
Damage analysis of masonry structures subjected to rockfalls
}

\author{
O. Mavrouli' ${ }^{1}$, P. G. Giannopoulos ${ }^{2}$, J. M. Carbonell ${ }^{3}$ and C. Syrmakezis ${ }^{2}$ \\ 1 Division of Geotechnical Engineering and Geosciences, Universitat \\ Politècnica de Catalunya (UPC-BarcelonaTech) \\ ${ }^{2}$ National Technical University of Athens, Institute of Structural Analysis \& \\ Antiseismic Research \\ 3 International Center for Numerical Methods in Engineering (CIMNE), \\ Universitat Politècnica de Catalunya (UPC-BarcelonaTech)
}

\begin{abstract}
Masonry structures present substantial vulnerability to rockfalls. The methodologies for the damage quantification of masonry structures subjected to rockfalls are scarce. An analytical procedure for the damage assessment of masonry structures is presented. The procedure comprises three stages: (1) Determination of the rockfall impact actions which are applied to a masonry structure, in terms of external forces, using the Particle Finite Element method PFEM; (2) Evaluation of the mechanical properties, modelling of the masonry structure, and calculation of the internal stresses, using the finite element method FEM; (3) Assessment of the damage due to the rockfall actions, applying a failure criterion adapted to masonries, and calculation of the damage in terms of the percentage of the damaged wall surface. Three real rockfall events and their impact on buildings are analysed. A sensitivity analysis of the proposed procedure is then used to identify the variables that mostly affect the extent of the wall damage, which are the masonry width, the tensile strength, the block diameter and lastly, velocity.
\end{abstract}

\section{Introduction}

Rock falls are very frequent soil instabilities occurring in cut and natural slopes and coasts. During a rockfall, the high velocity of the fall reduces critically the reaction time of individuals and communities. Protection measures, as nets and barriers, are common ways of prevention. However, if they do not exist or they are ineffective, significant structural and non-structural damage maybe caused to buildings and their occupants.

Although sophisticated methods for the analysis of the stability of rocky slopes exist (Corominas et al. 2014), the rockfall vulnerability assessment of structures is poor and mainly empirical, resulting in uncertain loss predictions (Papathoma-Kohle et al. 2007). For big rockfall events, the loss due to the impact of rock boulders on buildings is expected to be very high. Nevertheless for small and medium-sized events, this loss varies. The vulnerability of buildings in rockfall prone areas, when expressed in quantitative terms, can provide an objective parameter for the costbenefit analysis for the protection interventions. To this aim the objective here has been the assessment and quantification of the rockfall vulnerability of buildings.

To assess the vulnerability level of a structure, four main groups of methods exist (UNDP/UNESCO, 1982): (i) Categorization methods, based on the typological classification of structures into typological classes; (ii) Inspection and rating (empirical) methods, with an attribution of numerical value to each structure; (iii) Analytical methods, based on the analysis of a structure for the estimation of its expected resistance at an accidental event; (iv) Experimental methods, including tests for the determination of the structural properties of the whole structure and its components. Several researchers have proposed analytical methods for the evaluation of the vulnerability of buildings impacted by rapidly moving landslides such as debris flows (Fuchs 
et al. 2007; Totching and Fuchs 2013; Quan Luna et al. 2011) and snow avalanches (Bertrand et al. 2010).

The rockfall vulnerability has been in generally quantified to a lesser extent, mostly by means of empirical evaluations (Agliardi et al. 2009; Glade and Crozier 2005) without differentiating between typological classes. The response of structural elements to boulder impacts has been further investigated for embankments and protection structures (Volkwein et al. 2011), using empirical, analytical and experimental methods, as far as it concerns the impact loads, the energy transfer from the boulder to the structural elements and the response of the latter. Mavrouli and Corominas (2010a, 2010b) and Mavrouli et al. (2014) presented a method for the vulnerability assessment of reinforced concrete buildings. However, these results cannot be generalised to different structural typologies from the studied ones, as the structural performance of a building is strongly influenced by its geometry, load-bearing system and materials. Although masonries are common typologies in mountainous rockfall prone areas worldwide, the rockfall vulnerability of masonry buildings has received little attention so far.

As real events indicate, certain masonry structures retain substantial vulnerability to the dynamic impact of rockfalls. This is due to the brittle nature of the unreinforced masonry elements and their general design without considering loads with direction out of their plane (Schmidt and Cheng 2009). Masonry is an assemblage of units (stone blocks, bricks etc.) and mortar joints. Lourenço (2008) presents the most common masonry types, depending on the materials and their configurations. The response of the masonries to external actions presents many sources of uncertainties (Mojsilovic and Faber 2008), therefore in order to describe it, a probabilistic approach is preferred instead of a deterministic one. The probabilistic approaches, exactly as the deterministic ones, require the application of models and methodologies for the assessment of the structural response of buildings subjected to rockfalls.

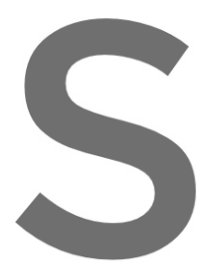

The numerical analysis of masonry buildings can indicate their expected performance to given rockfall impacts, independently of the existence of empirical data. It can provide a tool for
assessment of the damage, which takes into consideration specific typological dasses and
characteristics, and provides distinct damage degrees for given rockfall magnitudes and
intensities. The masonry analysis requires methodologies that can incorpdrate its peculiarities
with respect to the heterogeneity and variability of the composite materials, the orthdtropy along
its two directions with reference to the horizontal and vertical joints planes, its low tensile strength,
and the statically indeterminate load-bearing system.

problems. Different alternatives exist for the constitutive modelling and the homogenisation of the materials (Lourenço 1996), the consideration of non-linearities (Burnett et al. 2007; Wu and Hao 2006) and two or three dimensional configurations (Syrmakezis et al. 2005c). Syrmakezis et al. (2005a, 2005b, 2006) proposed a complete stress and failure analysis of masonry structures subjected to out-of-plane earthquake loading using the finite-element method to calculate model stresses, displacements and dynamic structural properties (i.e. eigen-period). In that methodology the first stage finite element analysis information is completed by a failure analysis, applying a failure criterion especially adapted to masonry structures (Syrmakezis and Asteris 2001). In this way, problematic areas on the structure can be located, possible causes of failure can be quantified, and the expected damage can be specified on a qualitative and quantitative basis. The failure analysis was performed using the software FAILURE. Using the results of this analysis Marinelli et al. (2004) have provided a procedure for incorporating the uncertainties which are involved in the seismic response of masonry structures, using fragility curves.

The works on the behaviour of masonries subjected to impacts by drop-weights are scarce, while most of them focus on the seismic (DeJong 2009) or blast (Milani and Lourenço 2009; Mayrhofer 2002) actions. Lourenço et al. (2010) studied the impact behaviour of masonry arches using the finite element method for high strain-rate loads (impulses). Schmidt and Cheng (2009) developed a finite element model for the analysis of the out-of-plane impact response of unreinforced masonry walls proposing a constitutive model for the simulation of contact forces between a moving mass and a wall. Burnett et al. (2007) used linear elastic solid elements for masonry units in conjunction with a specially formulated contact interface model for masonry joints; they developed a simplified discrete-crack finite element approach to model unreinforced brickwork and blockwork masonry walls subjected to out-of-plane impacts. These models work for lowvelocity impacts. There is a lack of studies on the performance of masonries subjected to high- 
velocity rockfall impacts. Hence, there is a need to provide methodologies that take into consideration the impact forces that are developed on a masonry wall due to the wall-boulder interaction and that can provide a measure for its damage. It is the aim of this work to bridge this gap.

We focus on a methodology that analyses masonry structures and assesses their damage, according to Syrmakezis et al. (2005a, 2005b, 2006) including calculations for both stresses and failure. The degree of damage is, then, provided as the percentage of the area that failed (its resistance was exceeded by the rockfall actions). Using this process, we analytically examined three different rockfalls in the Pyrenees, leading to the impact of rock boulders on buildings. Given the size of the rock boulders, we calculated the damage, its pattern and extent, and we compared it with the observed damage.

To adapt this methodology to rockfall impacts a further step is proposed. This step aims at calculating the impact force that is applied to a masonry wall by a rock boulder, considering the wall characteristics and the boulder kinematic properties (size and velocity). Due to the high stress-rate of the rockfall impact, it is important to incorporate the effect of the impact velocity and the wall/boulder interaction.

The proposed procedure is applied to identify the variables that mostly affect the wall vulnerability performing a sensitivity analysis. These variables refer to the characteristics of the masonry and of the rock boulder at the moment of the impact. These factors should be taken into consideration when assessing the vulnerability and the risk.

This work forms part of an ongoing work on the vulnerability of masonry buildings subjected to rockfall impacts. It is intended to use it for the assessment of the response of a variety of structural typologies to a series of rockfall impacts, and the development of fragility curves for a wide range of applications
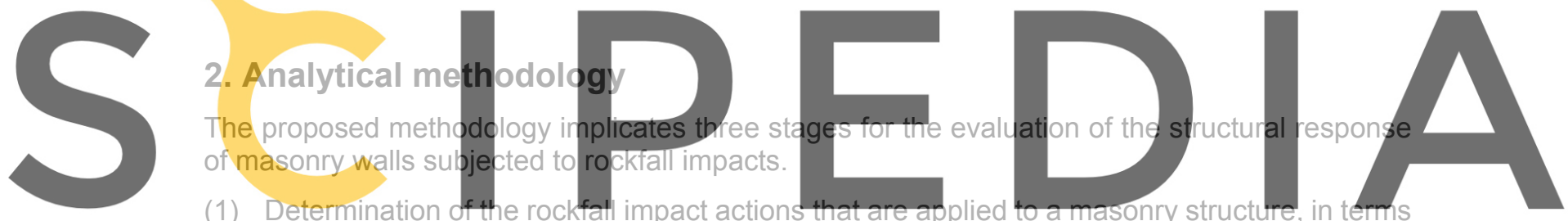
of external forces, using the Particle Finite Element method PFEM.

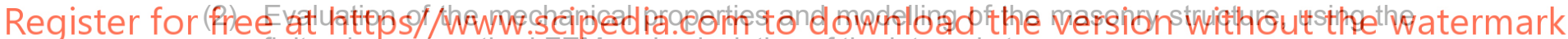
finite element method FEM and calculation of the internal stresses.

(3) Assessment of the damage of the masonry structure, applying a failure criterion on the resuits of step (2) and using the software FAILURE (Syrmakezis and Asteris 2001); quantification of the damage in terms of percentage of the damaged wall surface.

These steps are explained in the following sections.

\subsection{Rockfall actions on masonry walls}

The simulation of the interaction between an impacting boulder and a masonry wall, including the transmission of the impact energy between them, is a complex issue due to the large number of involved factors: the relative masses, stiffnesses and velocities of the rock block and the wall, the contact zone, the loading time-history, the impact precision, and the area of the absorbed local energy.

In order to quantify the impact forces and the energy absorbed by the wall, the masonry walls should be modelled. Due to the in-homogeneities characterizing such structures, both modelling and numerical simulations are hard to be treated in a standard way. Although masonry is not an homogeneous material, a simplified option to evaluate its response is to model it as a continuum body incorporating given isotropic average properties. When specific details on the possible cracking are required, the use of accurate and more sophisticated models is necessary instead, either for stone masonry walls (Ramakrishnan and Lourenço 2009) or for clay brick masonry walls (Bakhteri and Sambasivam 2003; Brasile et al. 2010; Bakhteri et al. 2004). In all cases, the Finite Element Method (FEM) is commonly used for this. The FEM formulates a solution on the 
mechanics of the continuum to represent the internal stress evolution of a medium under certain loading conditions.

To evaluate the impact forces, the contact zone and the resultant energy, the mechanical stresses that are developed during the contact should be also taken into account. The contact mechanics are characterized by complexity when it comes to their modelling and numerical simulation. In the case of an impact of a rock boulder with a masonry wall, both parts can be considered deformable. The results vary depending on the stiffness of each part, and this makes the analysis of the interaction of the two bodies more complex. A considerable deformation of the softer media affects the contact area. Hence if there is an impact, the impact-induced acceleration and the dynamics of the interaction must be taken into account. All these aspects introduce a large set of new non-linearities to the model.

In this work, one of the objectives was to use a method suitable to capture the impact characteristics of a rock boulder on a masonry wall and able to surpass all modelling complexities. For this reason the Particle Finite Element Method (PFEM) joined with the Contact Domain Method (CDM) is proposed.

The PFEM is founded on the Lagrangian description of particles and motion and it combines a meshless definition of the continuum containing a cloud of particles with standard mesh-based finite element techniques. The initial developments of the Particle Finite Element Method (PFEM) took place in the field of fluid mechanics (Idelsohn et al. 2004; Oñate et al. 2004), because of the PFEM feasible features of tracking and modelling of free surfaces. Later on, the Particle Finite Element (PFEM) was applied in a variety of simulation problems and to solid mechanics. The first applications of PFEM to solid mechanics took place for problems involving large strains and rotations, multiple body contacts and creation of new surfaces (riveting, powder filling, ground excavation and machining) (Carbonell et al. 2013; Oliver et al. 2007).
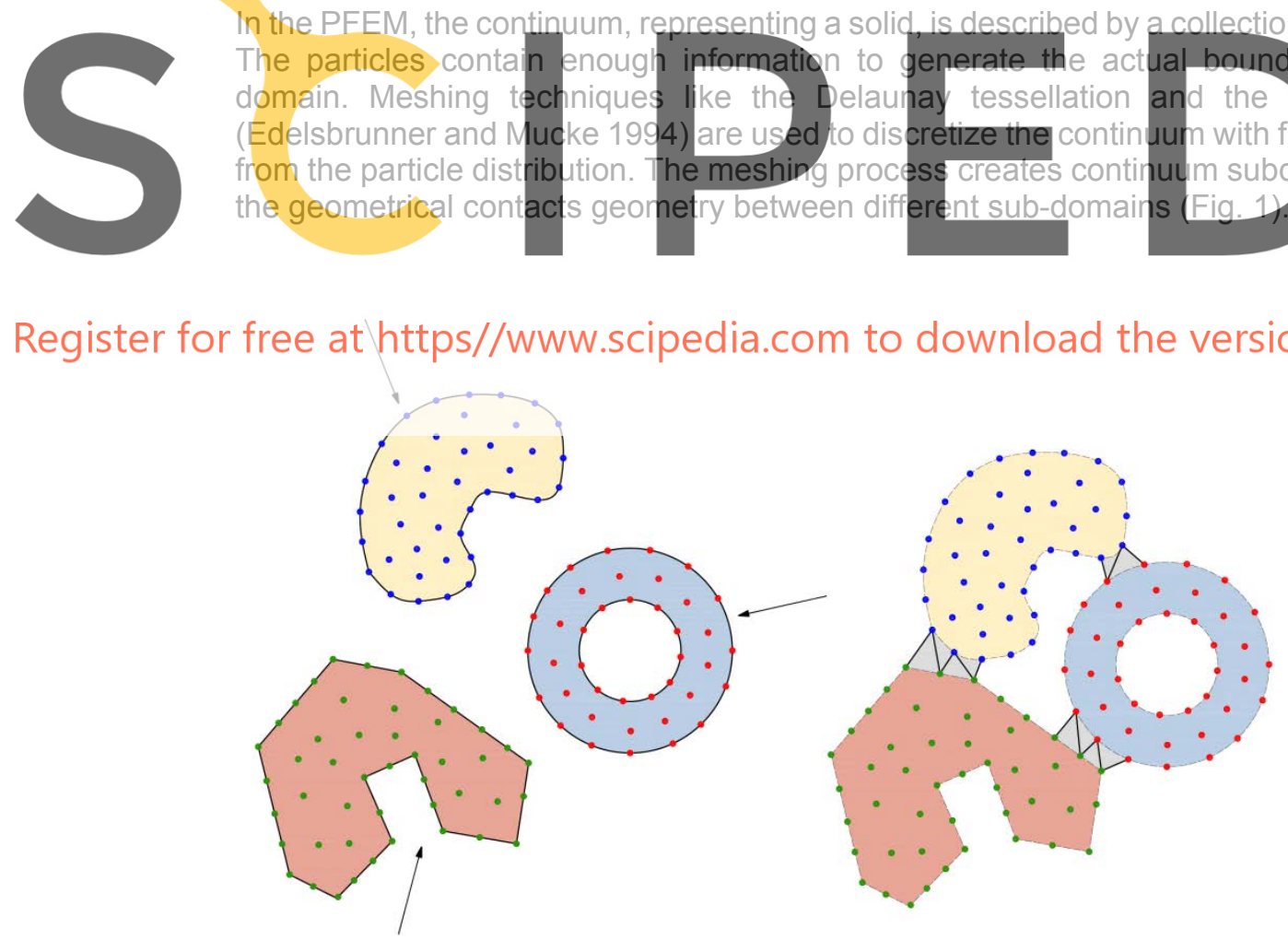

Fig.1 Using the alpha-shapes the detection of contact between sub-domains is automatically generated. Contact Domain elements are formed when the sub-domains are close enough. The identification of the continuum between subdomains is used for the definition of the contact set, which provides the active area of contact where the contact constraint is applied. The Contact Domain Method (CDM) is specially formulated to take into account the contact constraint defined by an interface finite element mesh (Oliver et al. 2009; Hartmann et al. 2009) 
Using the PFEM and the CDM the impact of the boulder against the wall can be simulated properly. For simplicity, and in order to define a useful representative model, we started with a definition of a two dimensional model consisting of:

(1) A wall defined by its height and thickness, fixed at the base and supported at the top. The masonry material characterized as an elastic material by the Young Modulus, the Poison Ratio and the Density.

(2) A rock boulder that can have different shapes. The first approach is a regular quadrilateral shape. The material is also considered elastic with a Young Modulus, Poison Ratio, and a Density. The boulder is considered stiffer than the wall and the material parameters are defined accordingly.

The self-weight is considered for both bodies, and the boulder is located next to the wall with an initial imposed velocity to set the movement against the wall.

To give a representative view of the analysis, some results are presented in Fig. 2 . In this example the wall has a height of 3 meters and a thickness of 0.6 meters. The rock boulder is a quadrilateral of $1 \times 1$ meters with an initial velocity of $5 \mathrm{~m} / \mathrm{s}$. Fig. 2 shows how the boulder-wall interaction is captured and the dynamic impact forces calculated at every time step of the analysis. The maximum displacements are also depicted. The contact domain elements are not shown. From this numerical simulation, the envelope for the maximum contact forces and also the stress distribution in the direction of the movement of the boulder can be extracted.
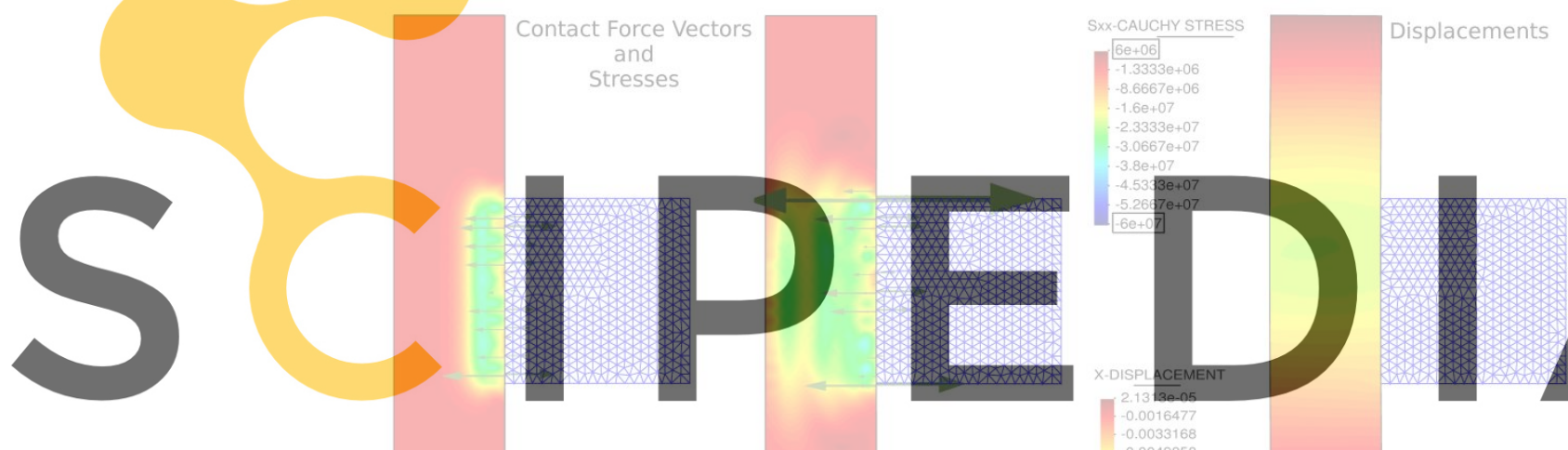

\section{Register for free at https//www.scipedia.com}

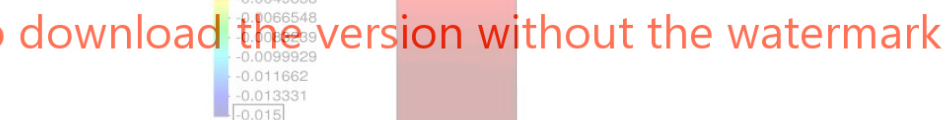

Fig.2 An indicative PFEM post-process model and results (horizontal contact stresses and displacements) for the impact of a rectangular boulder on an elastic wall with an initial velocity of $5 \mathrm{~m} / \mathrm{s}$, for different steps of the analysis

In the following section, the information from the numerical simulation is used in order to apply a representative pseudo-static force to the masonry wall domain that will represent the initial loading conditions for the next step of the procedure where a stress and failure analysis is performed.

In Fig. 3 and Fig. 4 we present an example considering isotropic damage for the constitutive behaviour of the masonry wall. The collapse of the wall can be observed. In Fig. 5 and Fig. 6 the same example, but with a different geometry for the boulder and isotropic damage for the masonry, is presented. It can be seen how the damage distribution and the contact surface experience a continuous change.

The results of Fig. 7 indicated that the absorption of the energy for the different models is substantially different (Fig. 7). For the elastic model, the obtained contact time interval is longer. The energy is not damped and multiple rebounds occur. Therefore if we consider the elastic case we err on the side of caution. 

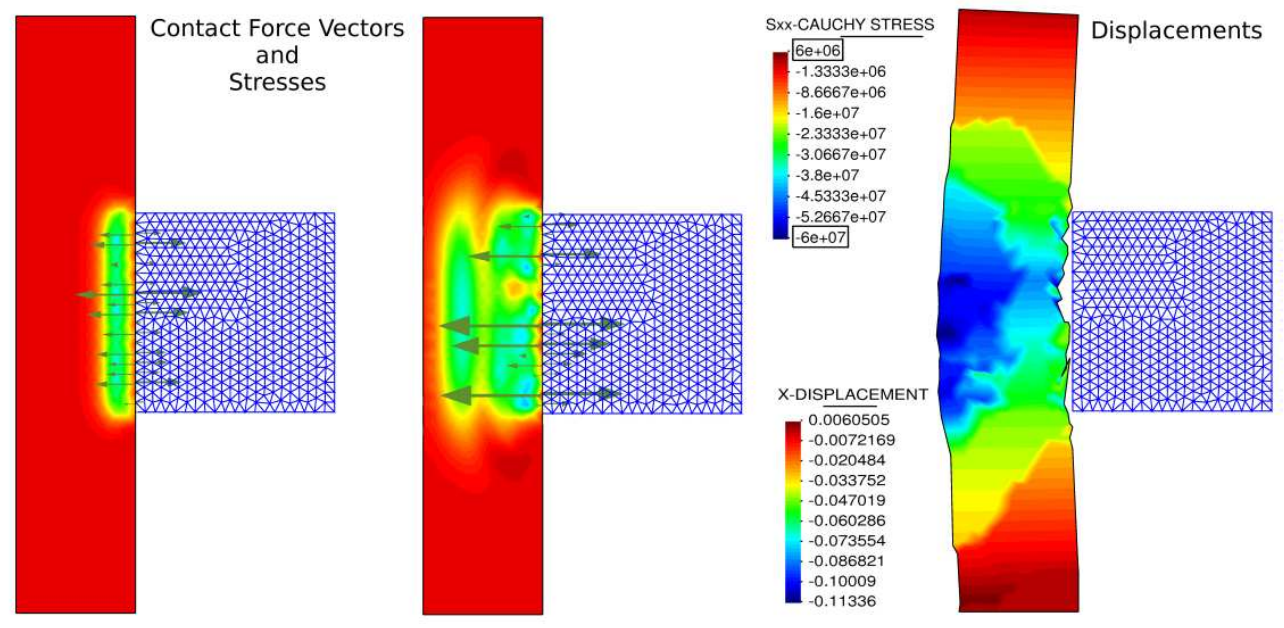

Fig. 3 Horizontal contact stresses and displacements. Impact of a rectangular boulder on a wall (considering isotropic damage) with an initial velocity of $5 \mathrm{~m} / \mathrm{s}$, for different steps of the analysis
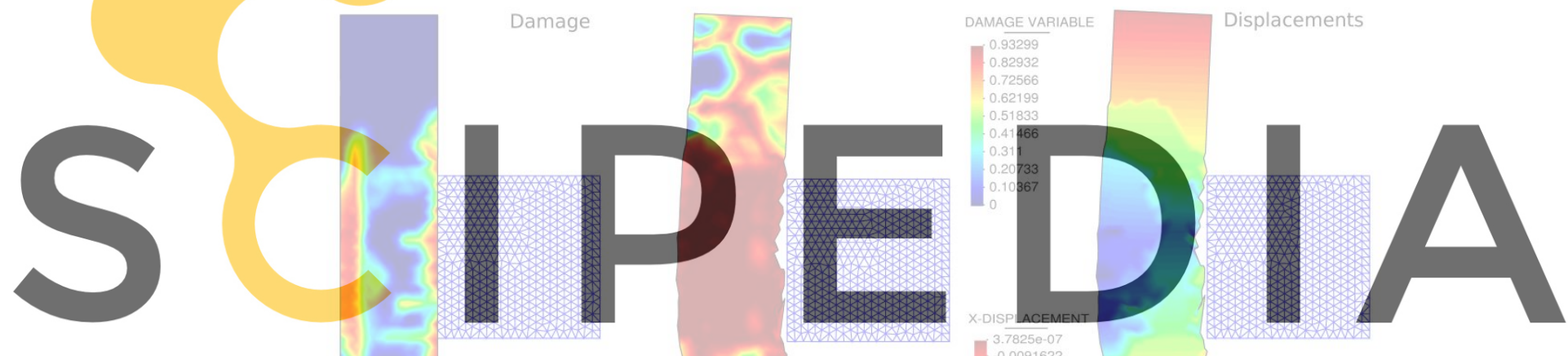

Register for free at https//www.scipedia.com to download the" version without the watermark

Fig. 4 Damage distribution and horizontal displacements. Impact of a rectangular boulder on a wall (considering isotropic damage) with an initial velocity of $5 \mathrm{~m} / \mathrm{s}$, for different steps of the analysis 


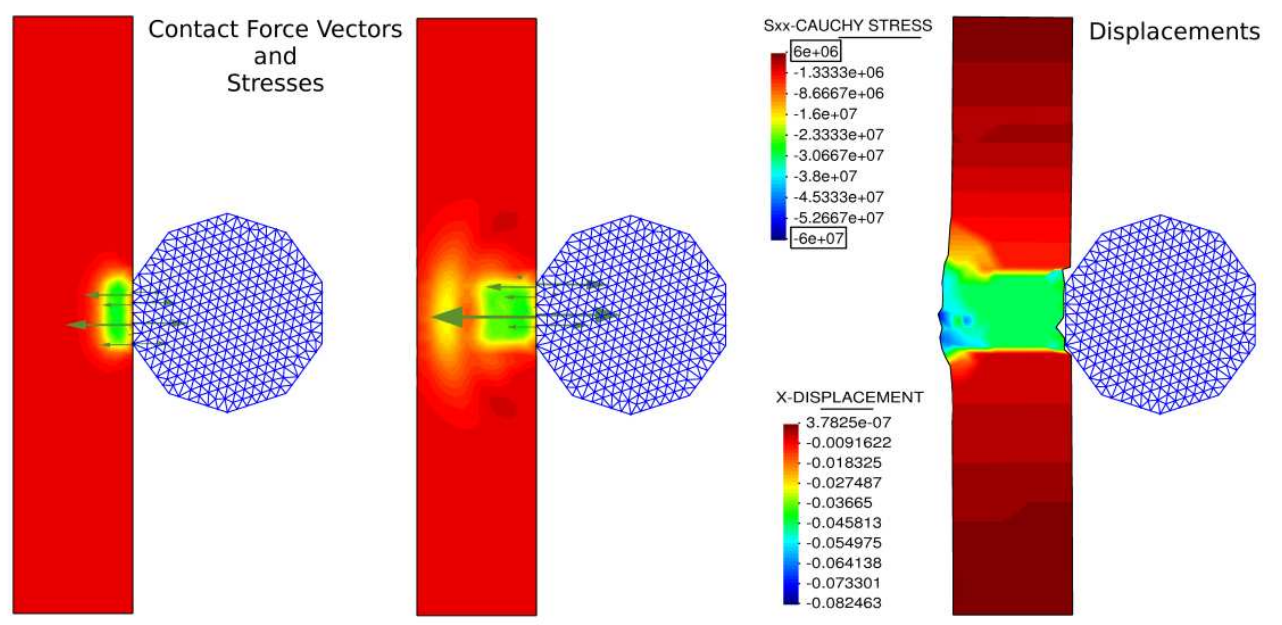

Fig. 5 Horizontal contact stresses and displacements. Impact of a spherical boulder on a wall (considering isotropic damage) with an initial velocity of $5 \mathrm{~m} / \mathrm{s}$, for different steps of the analysis

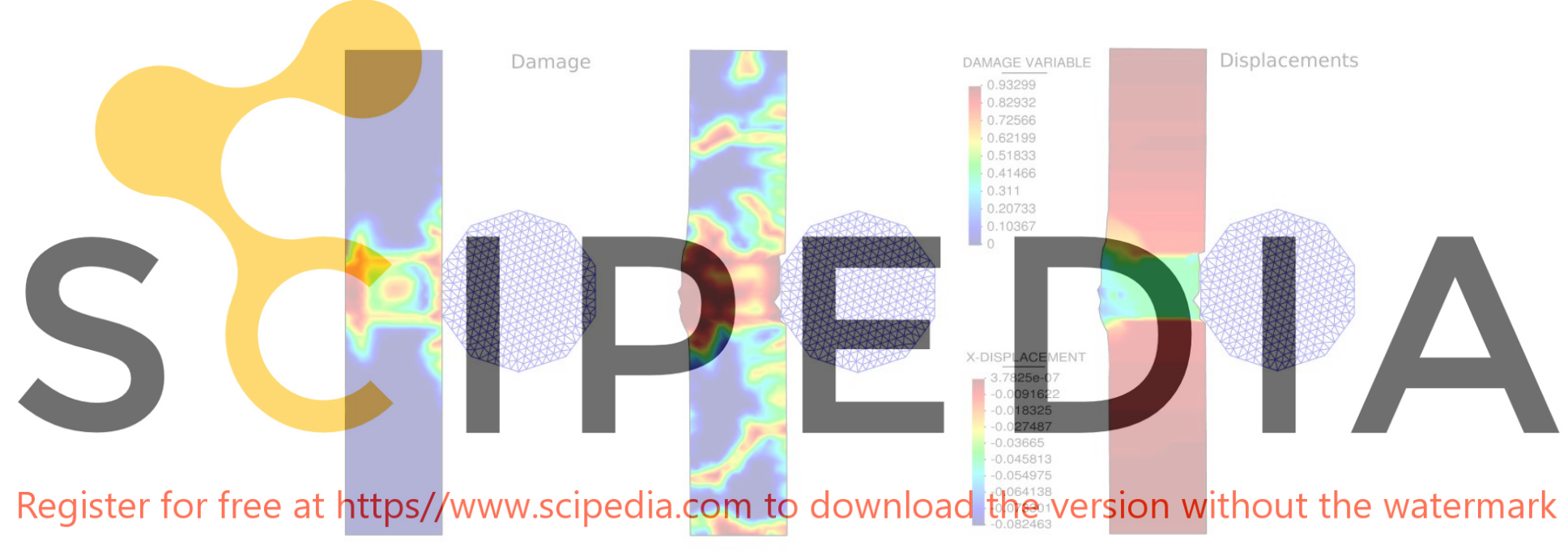

Fig. 6 Damage distribution and horizontal displacements. Impact of a spherical boulder on a wall (considering isotropic damage) with an initial velocity of $5 \mathrm{~m} / \mathrm{s}$, for different steps of the analysis 


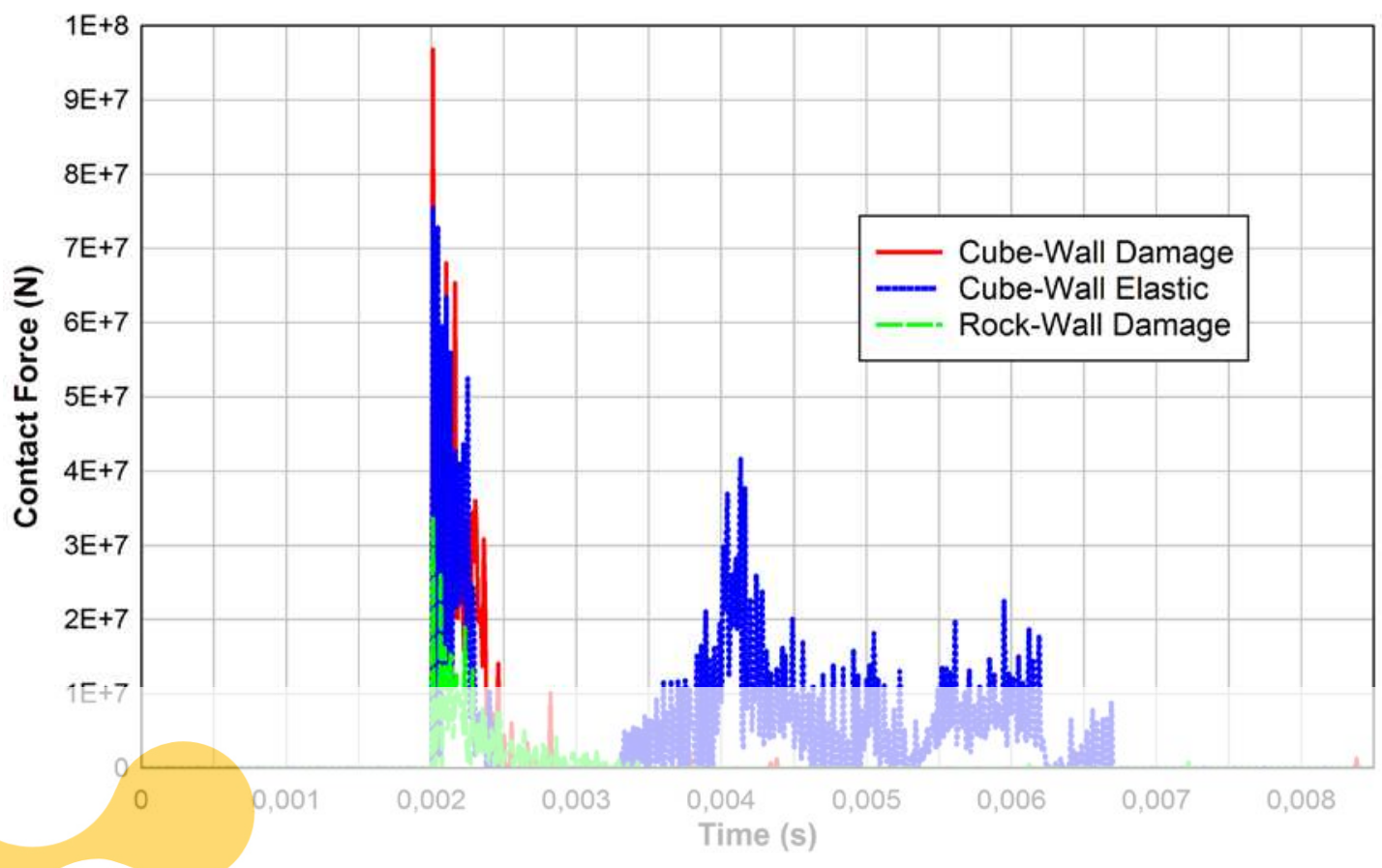

Fig. 7 Captured contact force for the three rock-wall impact examples shown. In the elastic case the contact time is approximately $6.5 \mathrm{~ms}$. When damage is considered the contact time is approximately $1.5 \mathrm{~ms}$
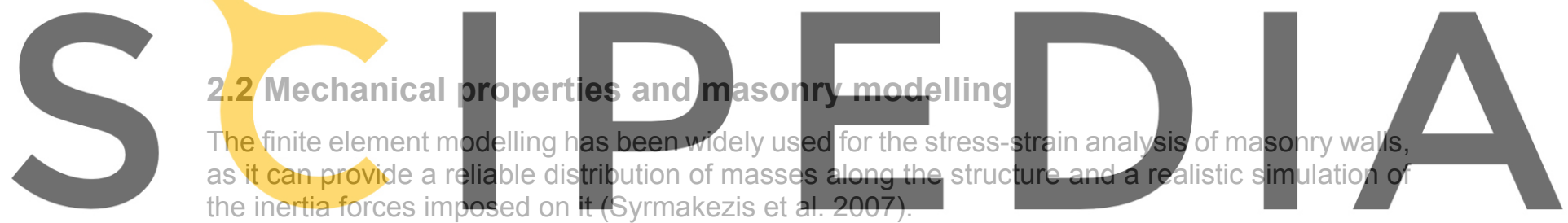
the inertia forces imposed on it (Syrmakezis et al

The out-of-plane analysis of masonry walls using the Finite Element Method FEM is performed

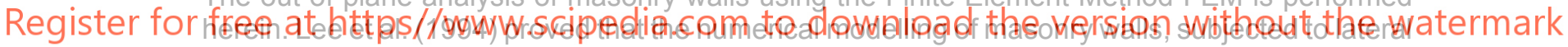
loading, assuming elastic-brittle behaviour, can efficiently predict their physical behaviour. This is also applied here. The three-dimensional modelling of the masonry is proposed. The most commonly employed finite element type for this purpose is the shell element. The modelling of masonry walls with a denser mesh near the rockfall application area is suggested.

Computational modelling frameworks for masonry structures range from simplified to complex nonlinear finite element or discrete element models. In most cases the macro-level nonlinear finite element models and homogenisation techniques are adopted. Attention has also been given to other methodologies (discrete element method, rigid block spring method, lattice modelling, discontinuous deformation analysis, combined discrete/finite elements), which deal more directly with the discontinuous nature of structural masonry in a simplified micro modelling manner. In large and practice-oriented analyses, the information concerning the interaction between masonry blocks and mortar is usually negligible for the global structural behaviour. Here, the finite element macro-modelling approach is followed, where the unit-mortar interfaces are smeared out in a homogeneous continuum. The macro-modelling strategy is thus used as distinct from the detailed micro-modelling and simplified meso-modelling ones, which consider the units and mortar distinctively (Lourenço 1996; Rots 1991).

For periodic masonries (with repeated units of blocks and mortar) macro-elements can be used with equivalent properties (Mavrouli and Syrmakezis 2008). For each element, the material is assumed to be linear elastic, isotropic and damage-free before loading, with its elastic properties defined by the elastic modulus and Poisson's ratio. The equivalent mechanical properties of the homogenised masonry (representing a composite of units and mortar) can be calculated according to Eurocode 6, CEN (2005) using the following expressions. The influence of the block size to the masonry properties was not considered here. 
The masonry compressive strength $f_{w c}$ is calculated by Equation (1) as recommended by Eurocode 6, CEN (2005):

$f_{w c}=K f_{b c}^{0.70} f_{m c}^{0.30}$

where

K: constant K (CEN 2005)

$f$ : the compressive strength of the blocks

$f:$ : the compressive strength of the mortar $\mathrm{mc}$

The masonry tensile strength $f$ can be evaluated according to CEN (2005) recommendations as well.

The modulus of elasticity $E_{c}$ (Young modulus) is calculated as:

$E_{c}=1000 * f_{W c}(2)$

The rockfall action is applied as an external pseudo-static force corresponding to the maximum contact force stress calculated using the PFEM, and determined for each combination of wall (characterised by its width), and rock boulder (characterised by its width, height and velocity). It is applied here as an external uniform stress perpendicular to the wall. The application area is central on the wall, and its height and width are equal to the boulder dimensions.

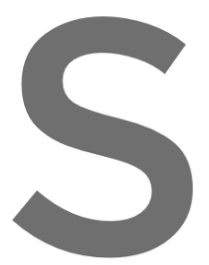

The resistance (stre

due to heterogeneity o th

source of uncertainty.

same applies for all

\subsection{Failure analysis}
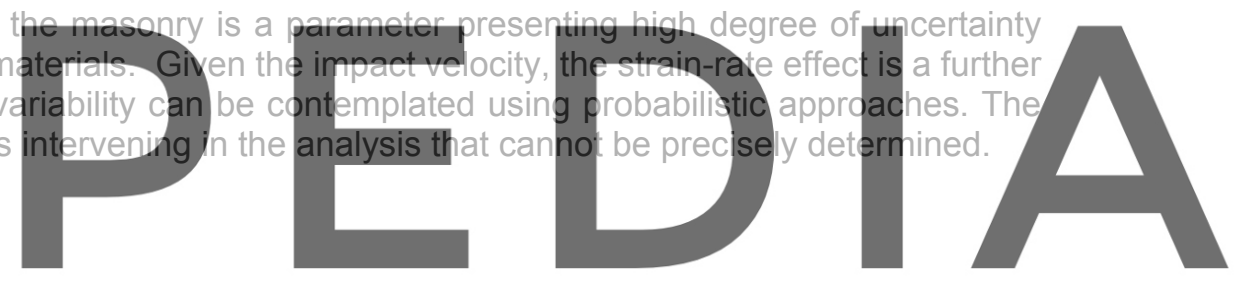

Register for failure analysis implies the use of a failure criteripn for the definition of the damaged areas of a

deformation. When bi-dimensional assumptions are made, a modified Von Mises criterion, using the two produced principal stresses, can be employed based on the Von Mises Theory. Modifications of the original criterion took place by Syrmakezis and Asteris (2001) in order to be consistent with masonry structural properties. The modified failure criterion is a semi-empirical failure criterion, based on experimental results.

The failure curve is formed by the interaction of four surfaces $S_{1}, S_{2}, S_{3}$ and $S_{4}$ as illustrated in Fig. 8 (section on the horizontal plane of zero shear stress). Each surface represents a certain biaxial stress state: $S_{1}$ represents a compression state in parallel to both principal axes, $S_{2}$ describes a stress state of tension in parallel to one principal axis and a stress state of compression in parallel to the other, $S_{3}$ represents a tension state in parallel to both principal axes and $S_{4}$ is symmetrical to $S_{2}$. An element is expected to fail when the applied direct and shear stresses specify a point on the circumference or outside the shaded area. The afore-mentioned curves are given by equations (3) to (6). 


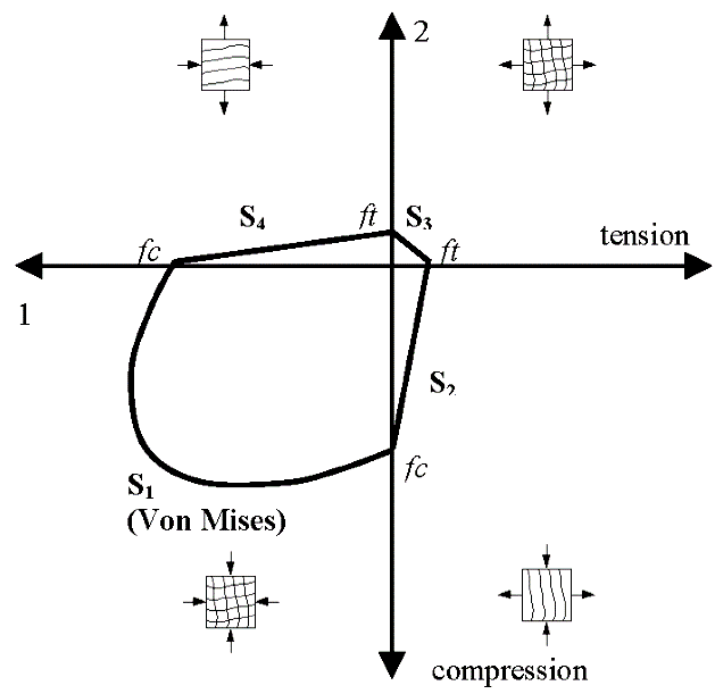

Fig. 8 Modified Von-Mises failure criterion for masonry structures

The surfaces which are illustrated in Figure 2 are given by:

$S 1=\sigma_{x x}^{2}+\sigma_{y y}^{2}-\sigma_{x x} \sigma_{x x}+3 \tau^{2}-f_{w c}^{2}=0$, for $\sigma_{x x}$ and $\sigma_{y y} \leq 0$

$S 2=\sigma_{y y}+\left(1-\sigma_{x x} / a\right)\left(f_{w C}^{2}-3 \tau^{2}\right)^{1 / 2}=0$, for $\sigma_{x x} \geq 0$ and $\sigma_{y y} \leq 0$
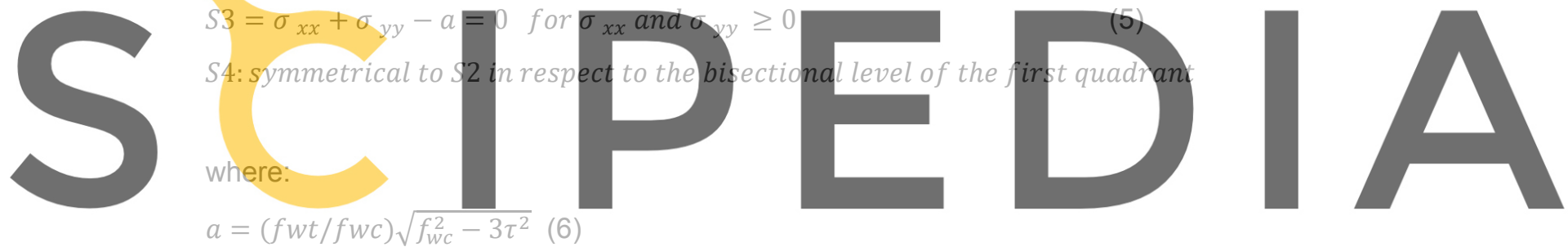

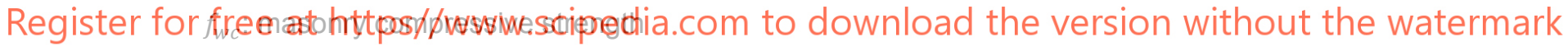

$f_{w t}:$ tensile strength

$\sigma_{x x}, \sigma_{y y}:$ principal stresses

T: shear stress

Failure analysis is carried out by application of the modified Von Mises failure criterion, introducing the max principal stresses $(\mathrm{T}=0)$ that result from the application of the rockfall actions, at every shell of the finite element model. The "FAILURE" software has been developed in Fortan by Syrmakezis and Asteris (2001) especially for this purpose.

"FAILURE" input data comprises three sets of information, specified for each plane: those concerning model definition, transformed stress analysis results on nodes and strength values in compression and tension. The stresses at every node and shell are checked against the failure criterion and the results are provided graphically, indicating which areas fail and the respective failure type (compression at both axes; compression at axis 1 and tension at axis 2; tension at axis 1 and compression at axis 2; tension at both axes). Graphical colour outputs of the failed areas are produced, for each plane. The percentage of the damage, expressing the percentage of the areas that fail, is additionally calculated by Equation (7).

Damage $(\%)=\frac{\text { Sum of fail areas }}{\text { Total } \text { wall area }}$ 


\subsection{Case studies}

To verify whether the proposed method for stress and failure analysis (sections 2.2 and 2.3) can reproduce realistically the failure patterns of a masonry wall that is subjected to a rockfall action, we analysed three real cases of rockfall impacts on buildings, all of them in the East Central Pyrenees.

The velocity of the impact is not known in any of these cases. There is in-situ evidence that as the boulders were moving downhills and before hitting the buildings, they lost a considerable part of their energy due to impacts with the ground, fragmentation and friction energy loss. The evaluation of this loss is a complicated issue and due to this a reliable estimation of the impact velocity was not possible. Thus in these analyses, the impact velocity was not included for the determination of the rockfall actions as suggested at section 2.1. Instead, the impact action was, simplistically and conservatively, simulated as the inertia force resulting, from the free fall on the walls, equal to the product of the rock mass with the gravitational acceleration.

The first case study is situated in Pont de Gullerí where a rockfall took place near the Sant Romà de Tavèrnoles village. The initial rockfall was about $2.5 \mathrm{~m}^{3}$, dropping from a height of $12 \mathrm{~m}$ and impacting on the ground before hitting the wall of a rubble masonry building, situated right at the bottom of the slope. The building and the breach in the wall are shown in Fig. 9. The wall width was $30 \mathrm{~cm}$. The blocks were irregular natural stones of varying dimensions of some centimetres, and in most cases with their horizontal dimension considerably longer than the vertical one. The mortar was very thin and of poor quality.

Some of the block fragments that were observed in the field, on both sides of the wall (inside and outside the building), were assumed to have been produced by the impact. There is in-situ evidence of the impact of the boulder on the rocky slope before flying and hitting the masonry.

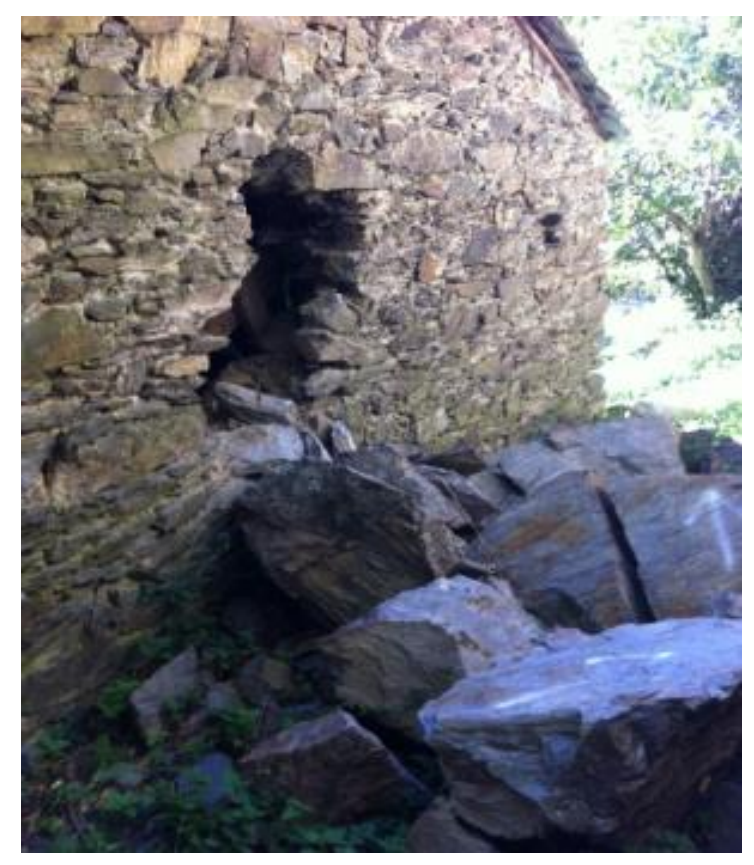

Fig. 9 The rockfall at Pont de Gullerí and the breach on the stone wall

The second case is a rockfall hit on a Roman church near the village Pessonada at the area of Pallars Jussà (Fig. 10). The structure was an ashlar masonry, with regular stone blocks of some centimetres and thin average quality mortar. In the area, there are several boulders from previous rockfall events, whose detachment has left visible on the slope face scars. A block of $0.25 \mathrm{~m}^{3}$ impacted on the church wall, but no damage was caused. 


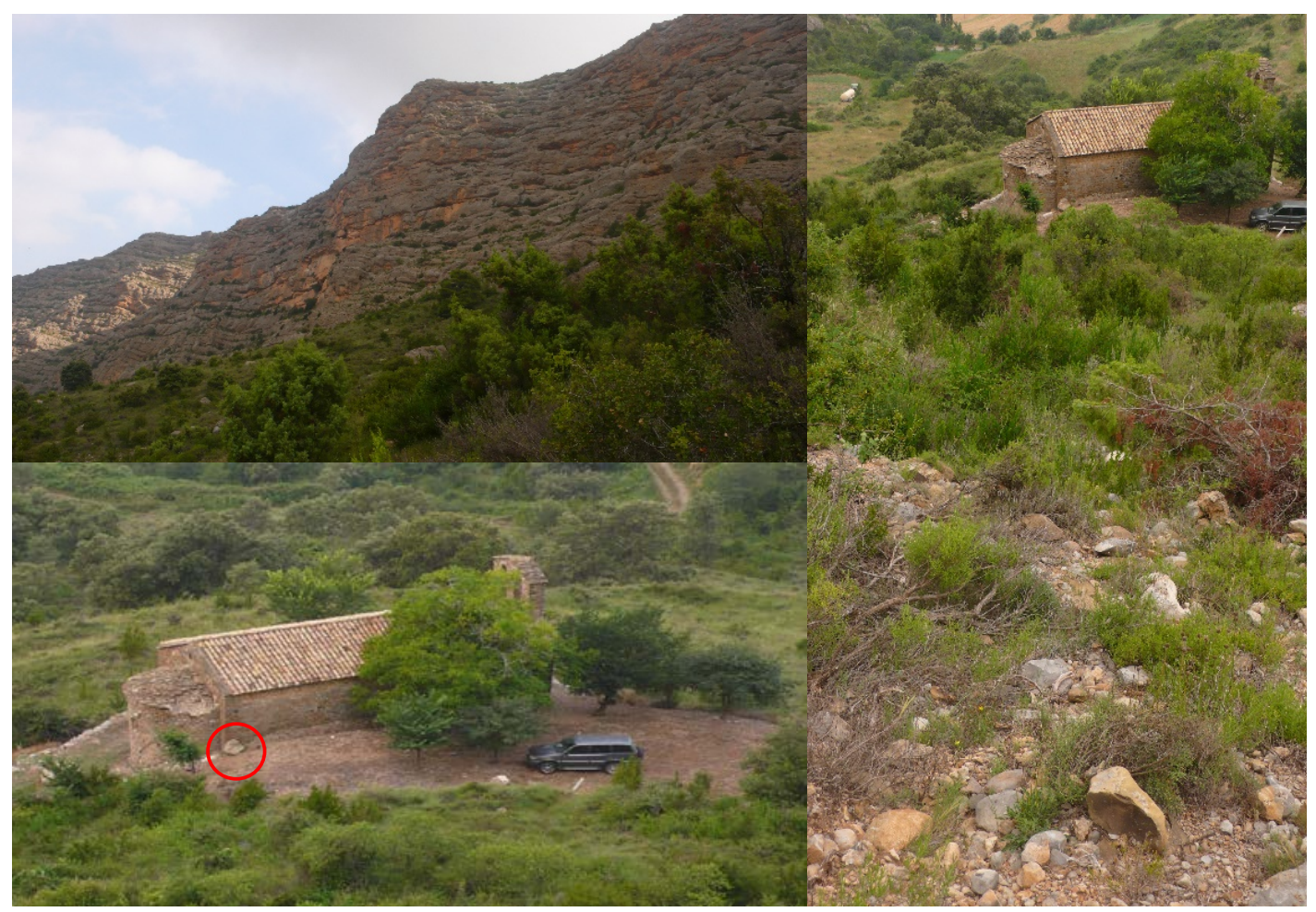

Fig. 10 The slope next to the village of Pessonada (up left) and the Roman church viewed from the slope (down left and right). In the red circle that boulder that hit the wall

The third case is the case of a rockfall which, in 2014, resulted in the impact of a block against a workshop in Santa Coloma, Andorra (Fig. 11). The initial rockfall fragmented into several boulders, one of which, of about $3.60 \mathrm{~m}^{3}$ damaged the workshop. The boulder impacted on the fence in front of the workshop before hitting the brick wall. The structure was a one-leaf clay brick masonry. The bricks were of standard dimensions of approximately $190 \mathrm{~mm}$ long x $90 \mathrm{~mm}$ wide x $90 \mathrm{~mm}$ high and cement mortar.

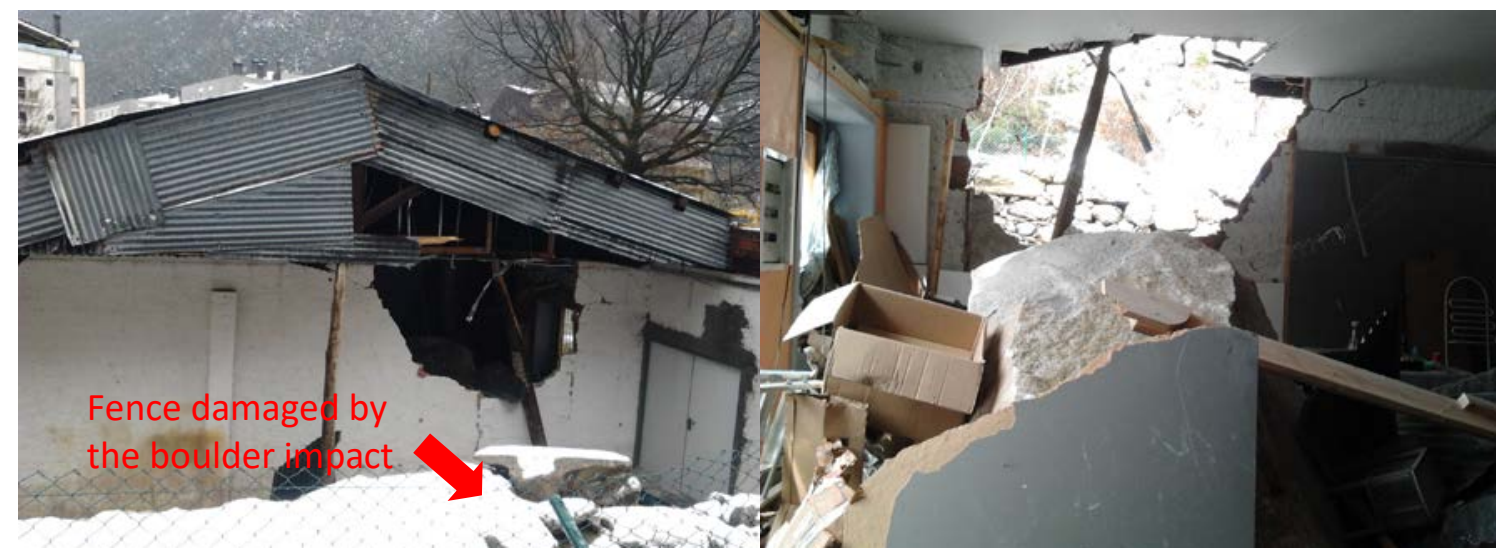

Fig. 11 Damage caused at a workshop in Andorra. Outside (left) and inside (right) view of the workshop

The three finite element models were developed using the software SAP2000. The initial stress state in the walls, before the rock block hit, resulted from their self-weight. The characteristics of the masonry properties for each structure are shown in Table 1. These are: masonry type, width, tensile and compressive strength, and modulus of elasticity. They were calculated according to the section 2.2. The compressive strength of the blocks was set in approximate terms according 
to values encountered in the literature for the materials at each site and in compliance with EC6 recommendations: for stone blocks and average construction quality at $50 \mathrm{MPa}$ at Pont de Gullerí, for stone blocks and good construction quality at $75 \mathrm{MPa}$ for Pessonada, and at $20 \mathrm{MPa}$ for brick blocks. The tensile strength of the masonry was defined according to the values proposed by EC6 for the characteristic initial shear strength, under zero compressive stress. We considered dimensioned natural stone and mortar M1-M2 for the buildings at Pont de Gullerí and Pessonada, and clay masonry units (bricks) and mortar M2.5-M9 for the one at Santa Coloma.

Table 2 resumes the impact characteristics that were used for the determination of the rockfall loading for each analysis: the block volume, the maximum impact stress and its application area. The application area of the impact force was defined by the interaction surface of the boulder with the wall, given the dimensions of each boulder. The impact stress was then determined distributing uniformly the impact force $\mathrm{F}$ over the application area.

Table 1 Masonry properties

\begin{tabular}{|l|l|l|l|l|l|l|l|}
\hline Location & Wall type & $\begin{array}{l}\text { Wall } \\
\text { width } \\
(\mathrm{m})\end{array}$ & $\mathrm{K}$ & $\begin{array}{l}\mathrm{f}_{\mathrm{bc}} \\
(\mathrm{MPa})\end{array}$ & $\begin{array}{l}\mathrm{f}_{\mathrm{mt}} \\
(\mathrm{MPa})\end{array}$ & $\begin{array}{l}\mathrm{f}_{\mathrm{wc}} / \mathrm{f}_{\mathrm{wt}} \\
(\mathrm{MPa})\end{array}$ & $\mathrm{E}(\mathrm{GPa})$ \\
\hline $\begin{array}{l}\text { Pont de } \\
\text { Gullerí }\end{array}$ & $\begin{array}{l}\text { Stone } \\
\text { masonry }\end{array}$ & 0.60 & 0.5 & 50 & 1 & $8 / 0.1$ & 0.9 \\
\hline $\begin{array}{l}\text { Pessonada, } \\
\text { Pallars Jussà }\end{array}$ & $\begin{array}{l}\text { Stone } \\
\text { masonry }\end{array}$ & 0.60 & 0.5 & 75 & 1.5 & $12 / 0.1$ & 1.1 \\
\hline $\begin{array}{l}\text { Santa } \\
\text { Coloma, } \\
\text { Andorra }\end{array}$ & $\begin{array}{l}\text { Brick } \\
\text { masonry }\end{array}$ & 0.19 & 0.5 & 20 & 2.5 & $5 / 0.2$ & 0.8 \\
\hline
\end{tabular}

Table 2 Rockfall impact properties

\begin{tabular}{|l|l|l|l|}
\hline Location & $\begin{array}{l}\text { Block volume } \\
\mathrm{m}^{3}\end{array}$ & $\begin{array}{l}\text { Impact stress } \\
\mathrm{KN} / \mathrm{m}^{2}\end{array}$ & $\begin{array}{l}\text { Impact Area } \\
\mathrm{m}^{2}\end{array}$ \\
\hline Pont de Gullerí & 2.80 & 42 & $1.0 \times 1.0$ \\
\hline $\begin{array}{l}\text { Pessonada, } \\
\text { Pallars Jussà }\end{array}$ & 0.28 & 24 & $0.5 \times 0.7$ \\
\hline $\begin{array}{l}\text { Santa Coloma, } \\
\text { Andorra }\end{array}$ & 3.60 & 39 & $1.4 \times 1.6$ \\
\hline
\end{tabular}

The maximum stresses, resulting from the FEM for each wall, were defined. Their distributions are graphically presented in Fig.12, where the application area of the boulder action is also indicated. Using the FAILURE software the damaged areas of the wall were identified. The results are shown in Fig. 13. These figures indicate the zones where the resistance of the masonry is exceeded, according to the Modified Von Mises failure criterion. These results reproduce efficiently the observed damage patterns on the walls, suggesting that the proposed method can be used for the assessment of the expected damage due to rockfalls. Although the velocity has not been considered here for the back analysis of these events, in the next section we demonstrate its incorporation for the refinement of the calculation of the maximum forces applied on a masonry wall, when the velocity data are known. 


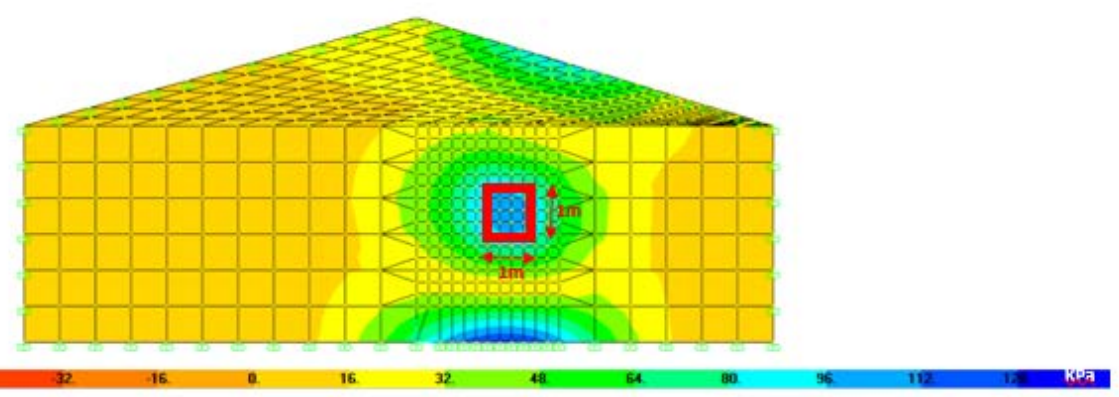

(a)

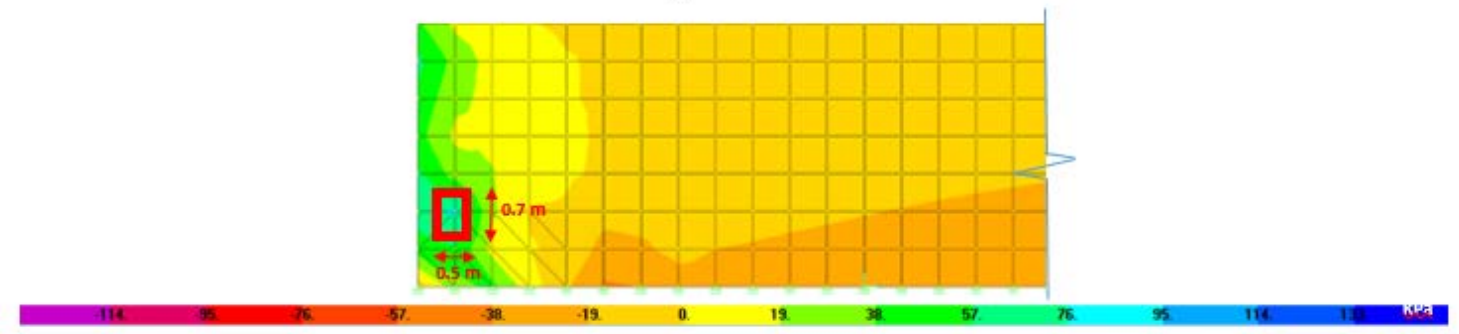

(b)

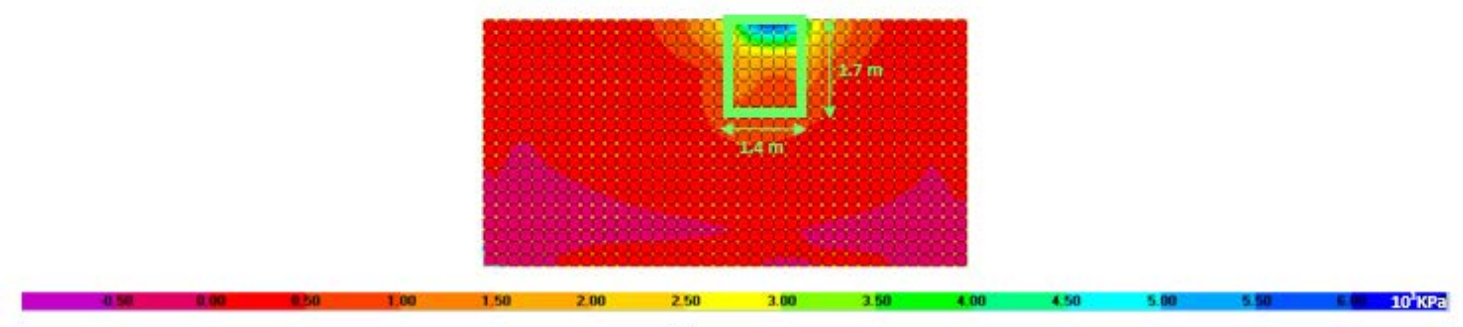

(c)

Fig. 12 Distribution of maximum stresses for the rockfall action for (a) Pont de Gullerí (b) Pessonada, Pallars Jussà and (c) Santa Coloma, Andorra. In green or red frame, the application area of the rockfall action 

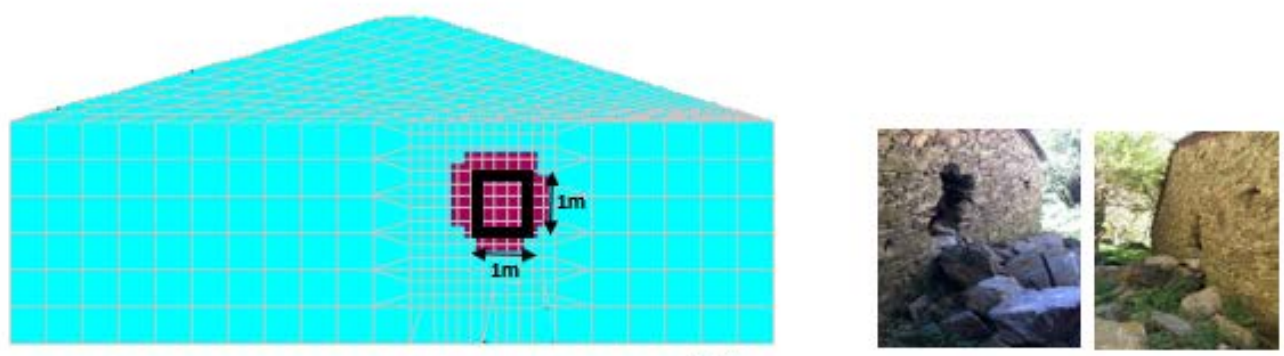

(a)
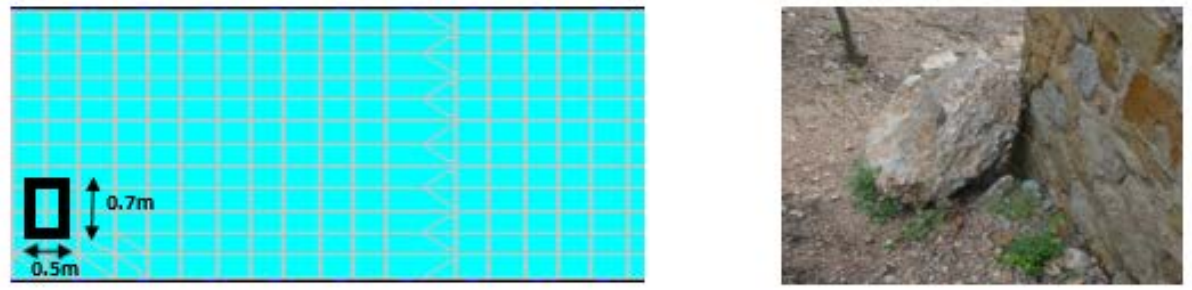

(b)
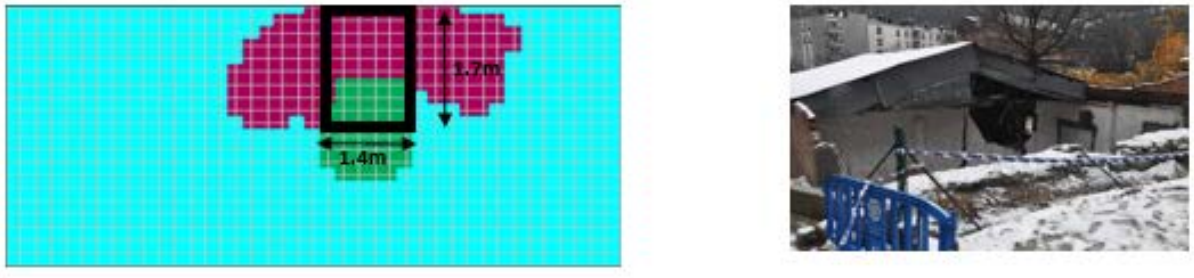

(c)

\section{Bi-axial tension \\ Tension/Compression \\ Compression/Tension \\ Bi-axial compression \\ No failure}

Fig. 13 Damaged areas (left) on the masonry wall. Black colour limits the rockfall application area and real damage (right) for (a) Pont de Gullerí (b) Pessonada, Pallars Jussà and (c) Santa Coloma, Andorra

\section{Sensitivity analysis}

To assess the vulnerability of a masonry panel subjected to a rockfall, the determination of the key factors that affect its behaviour is required. To this aim, a sensitivity analysis was performed to identify the model parameters exerting influence on the analytical results. The parameters (variables) that were analysed are: a) the masonry tensile strength, mainly related to the mortar tensile strength, b) the masonry compressive strength, mainly related to the blocks compressive strength, c) the wall width, d) the rock boulder diameter, and e) the rock boulder velocity.

The sensitivity analysis was performed for a masonry wall of $10 \mathrm{~m}$ length and $3 \mathrm{~m}$ height. The simulation model was fixed at its base, while the other three sides were pinned, in order to simulate the effect of two lateral transversal walls and a roof slab.

A range of values (Table 3 ) was assumed each time for one variable, which the rest of the variables were assumed constant. The ranges values were determined according to the values which are typically encountered for stone masonries in the literature (CEN 2005, MSJC 2008). The constant values were $0.15 \mathrm{MPa}$ for the masonry tensile strength, $1.13 \mathrm{MPa}$ for the masonry compressive strength, $0.6 \mathrm{~m}$ for the wall width and $1 \mathrm{~m}^{3}$ for the rock boulder volume. For the sensitivity analyses that were carried out with respect to the masonry tensile strength, the masonry compressive strength, the wall width, and the rock boulder volume, the rock impact action was equal to the inertia force resulting from the free fall on the walls, and the velocity was 
not included into the calculations. However, for the evaluation of the effect of the rock boulder velocity the method described at section 2.1 was used.

The proposed procedure was repeated to calculate the failure percentage for each case. Some indicative patterns of failure are depicted in Fig. 14. Fig. 15 presents the variation of the failure percentage for each variable.

Table 3 Range of variables for sensitivity analysis

\begin{tabular}{|l|l|l|}
\hline Variable & $\begin{array}{l}\text { Probabilistic } \\
\text { range }\end{array}$ & Units \\
\hline Masonry tensile strength & $0.02-0.3$ (every 0.02) & $\mathrm{MPa}$ \\
\hline Masonry compressive strength & $1.0-8.0$ & $\mathrm{MPa}$ \\
\hline Wall width & $0.2-1.6$ & $\mathrm{~m}$ \\
\hline Rock boulder volume & $1 ; 2.5 ; 5 ; 10 ; 20 ; 40$ & $\mathrm{~m}^{3}$ \\
\hline Rock boulder velocity & $0.5 ; 1 ; 2.5 ; 5 ; 10 ; 15 ; 30$ & $\mathrm{~m} / \mathrm{sec}$ \\
\hline
\end{tabular}

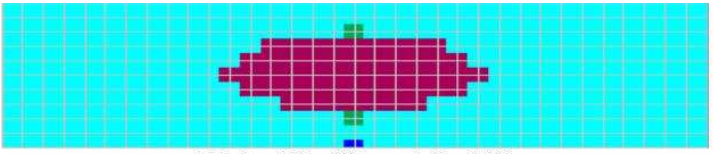

Wall width: $20 \mathrm{~cm}, \mathrm{Dl}=14 \%$

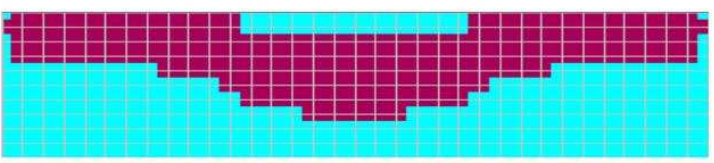

Wall tensile strength: $0.02 \mathrm{MPa}, \mathrm{DI}=41.56 \%$

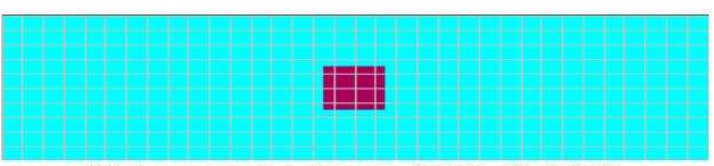

Wall compressive strength: $1 \mathrm{MPa}, \mathrm{DI}=2.34 \%$

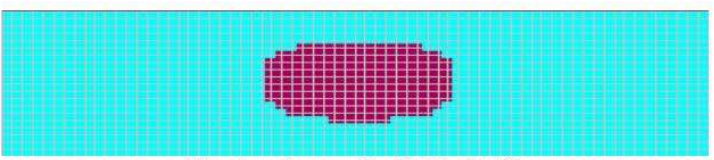

Block volume: $1 \mathrm{~m}^{3}, \mathrm{DI}=0.4 \%$

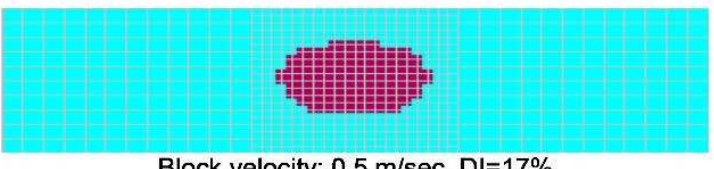

Block velocity: $0.5 \mathrm{~m} / \mathrm{sec}, \mathrm{DI}=17 \%$

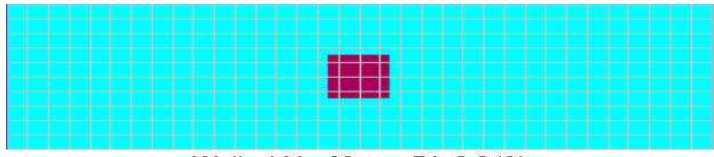

Wall width: $60 \mathrm{~cm}, \mathrm{DI}=2.34 \%$

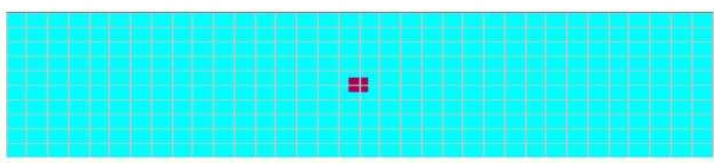

Wall tensile strength: $0.2 \mathrm{MPa}, \mathrm{DI}=0.26 \%$

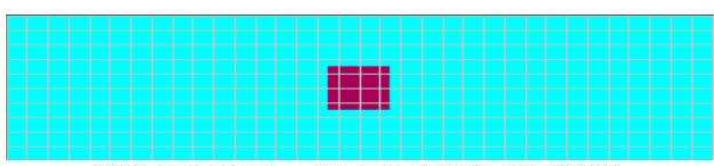

Wall compressive strength: $8 \mathrm{MPa}, \mathrm{DI}=2.34 \%$

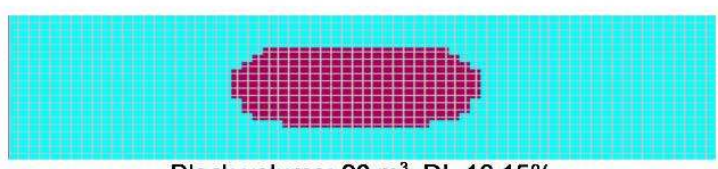

Block volume: $20 \mathrm{~m}^{3}$, $\mathrm{DI}=16.15 \%$

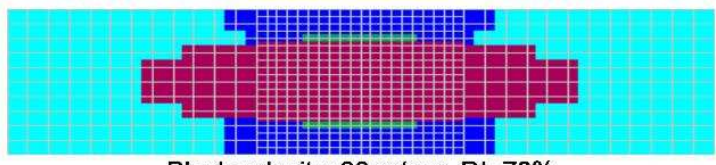

Block velocity: $30 \mathrm{~m} / \mathrm{sec}, \mathrm{DI}=70 \%$

\begin{tabular}{lll|l|l|l}
\hline Bi-axial tension $\square$ Tension/Compression & Compression/Tension & Bi-axial compression & No failure
\end{tabular}

Fig. 14 Indicative patterns of failure which were calculated for sensibility analysis 

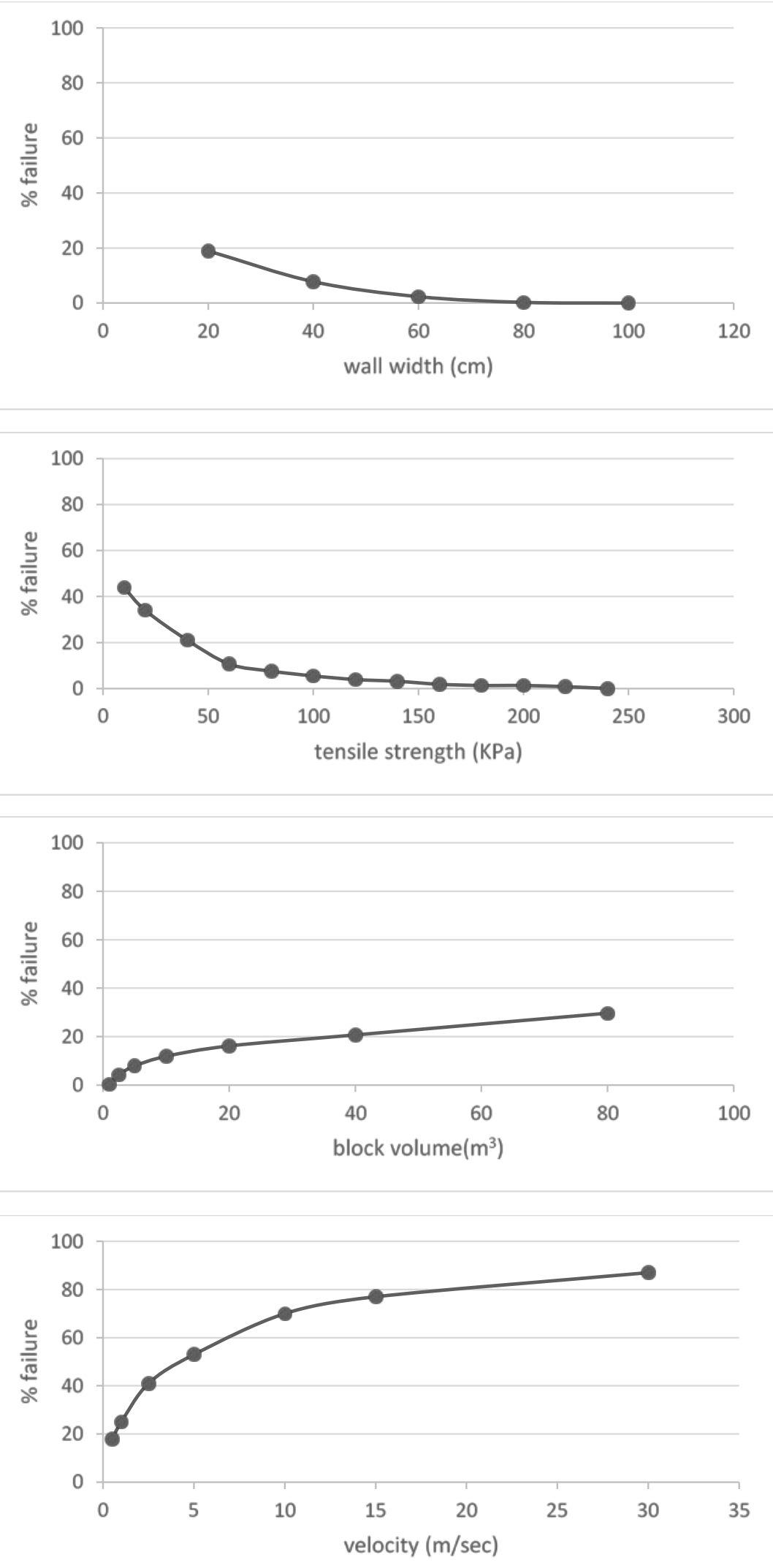

Fig. 15 Variation of the damage percentage for each variable (the fixed values for the sensitivity analysis are for the masonry tensile strength: $0.15 \mathrm{MPa}$, for the masonry compressive strength: $1.13 \mathrm{MPa}$, for the wall width: $0.6 \mathrm{~m}$, and for the rock boulder volume: $1 \mathrm{~m}^{3}$ ) 
The significance of each parameter was then determined by the Sensitivity Index SI (Equation 8) calculating the output difference (\%) when varying one input parameter, from its minimum to its maximum value (Hoffman and Gardner, 1983; Bauer and Hamby, 1991):

$$
S I=D I_{\max }-D I_{\min } / D I_{\max }
$$

where the indices $D_{\min }$ and $D_{\max }$ represent the minimum and maximum damage index values, respectively. $D_{\min }$ and $D_{\max }$ are obtained varying the input over its entire range (Hoffman and Gardner 1983). Values of the SI closer to 1 indicate higher importance of a variable.

The results (Table 4) indicate that the most important factors affecting the masonry performance, are the masonry width and tensile strength, followed by the rock boulder volume and its velocity. The wall width was also indicated to be a very important factor especially for masonries thinner than $60 \mathrm{~cm}$. For the compressive strength analyses, the damage did not experience any variation as the wall would first fail due to biaxial tensile strength.

Table 4. Sensitivity Index values

\begin{tabular}{|l|l|}
\hline Variable & Sensitivity Index \\
\hline Wall width & 1.00 \\
\hline Masonry tensile strength & 1.00 \\
\hline Masonry compressive strength & 0.00 \\
\hline Rock boulder volume & 0.99 \\
\hline Rock boulder velocity & 0.79 \\
\hline
\end{tabular}

\section{Conclusions}

Rock boulder impacts on masonry buildings may cause variable damage. For big rockfall events, the loss is expected to be very high. Nevertheless for small and medium-sized events, this loss depends on the boulder magnitude and kinematics, as well as the building characteristics (geometry, materials, strength, supports...). Although the evaluation of the expected damage for buildings is necessary for the rockfall risk assessment, the methodologies that take these issues into consideration are scarce. In this paper a numerical method is proposed for the damage assessment. The simulation of real rockfall impacts on masonries indicates that the methodology can successfully reproduce the pattern of the damage and it can be used for damage prediction.

This methodology has the advantage of taking into account all stages of the phenomenon. In the first stage, the Particle Finite Element Method (PFEM) is used to model the impact of the rock boulder with the masonry structure. This analysis provides an assessment of the maximum impact forces due to rockfall actions, in function of the velocity and the size of the boulders. The results of the performed analyses, provide an indication of the actions to be expected at similar rockfall impacts on masonries. These results should be carefully interpreted, as the analysis mainly aims at the provision of an indication of the response instead of a unique solution to a given problem.

In the second stage, the structural performance is analysed in terms of structural damage. The FAILURE software was employed after the FEM analyses to detect the damage. The severity of the computed damage is determined by the percentage of the damaged area and accordingly of the zone that needs to be repaired. This percentage can be directly used for the quantitiative rockfall risk assessment.

The sensitivity analysis indicates that the most important factors affecting the damage are in descending order the masonry width, the tensile strength, the block diameter and the block velocity. The wall width is also one of the most important factors especially for masonries thinner 
than $60 \mathrm{~cm}$. The tensile strength plays a primary role in comparison with the compressive strength.

The procedure presented herein, has been developed as a first step for the probabilistic vulnerability assessment of masonry buildings subjected to rockfalls, using fragility curves. However it can be a useful contribution for applications that involve the investigation of the outof-plane response of masonry walls, subjected to ballistic loading.

\section{Acknowledgments}

This work has been realized within the framework of the fellowship "Ayudas Fundación BBVA a Investigadores, Innovadores y Creadores Culturales" by the Foundation BBVA and the research project RockRisk financed by the Spanish Ministry of Economy and Competitiveness (BIA201342582-P).

\section{References}

Agliardi F, Crosta GB, Frattini P (2009) Integrating rockfall risk scenario assessment and countermeasure design by 3D modelling techniques. Nat Hazard Earth Sys 9:1059-1073

Bakhteri J, Sambasivam S (2003) Mechanical Behavior of Structural Brick Masonry: An Experimental Evaluation. Proceedings of 5th Asia-Pacific structural Engineering and construction conference Malaysia 305- 317

Bakhteri J, Makhtar A, Sambasivam S (2004) Finite element modelling of structural clay brick masonry subjected to axial compression. Jurnal Teknologi 41B (2004): 57-68

Bertrand D , Naaim M, Brun M (2010) Physical vulnerability of reinforced concrete buildings impacted by snow avalanches. Nat. Hazards Earth Syst. Sci. 10:1531-1545

Brasile S, Casciaro R, Formica G. (2010) Finite element formulation for nonlinear analysis of masonry walls. Comput Struct 88(3): 135-143.

Burnett S, Gilbert M, Molyneaux T, Beattie G, Hobbs B (2007) The performance of unreinforced masonry walls subjected to low-velocity impacts: Finite element analysis. Int J Impact Eng 34(8): 1433-1450

Carbonell JM, Oñate E, Suárez B (2013) Modeling tunnelling processes and rock cutting tool wear Particle Finite-Element Method. Comput Mech 52: 607-629

CEN (2005) Eurocode 6: design of masonry structures-part 1-1: common rules for reinforced and unreinforced masonry structures. EN 1996-1-1:2005. Brussels

Corominas J, Westen C, Frattini P, Cascini L, Malet J-P, Fotopoulou S, Catani F, Eeckhaut, O Mavrouli M, Agliardi F, Pitilakis K, Winter M G, Pastor M, Ferlisi S, Tofani V, Hervás J, Smith $\mathrm{T}$ (2014) Recommendations for the quantitative analysis of landslide risk. Bull Eng Geol Environ 73 (2): 209-263

DeJong MJ (2009) Seismic Assessment Strategies for Masonry Structures, PhD dissertation, Massachusetts Institute of Technology, 2009. Available at: http://web.mit.edu/masonry/papers/DeJong_PhD_2009.pdf. Accessed 17 August 2015 
Edelsbrunner H, Mucke EP (1994) Three-dimensional alpha shapes. ACM Trans Graph 13(1):4372

Fuchs S, Heiss K, Hübl J (2007) Towards an empirical vulnerability function for use in debris flow risk assessment. Nat Hazard Earth Syst 7:495-506

Glade T, Crozier M (2005) The nature of landslide hazard impact. In: Glade T, Anderson M, Crozier M (eds) Landslide hazard and risk. Wiley, Chichester, pp 43-74

Hartmann S, Oliver J, Weyler R, Cante JC, Hernández JA (2009) A contact domain method for large deformation frictional contact problems. Part 2: Numerical aspects. Comput Method Appl M 198(33): 2607-2631

Idelsohn SR, Oñate E, Pin FD (2004) The particle finite element method: a powerful tool to solve incompressible flows with free-surfaces and breaking waves Int J Numer Meth Eng 61: 964-989

Lee JS, Pande GN, Middleton J, Kralj B (1996) Numerical modelling of brick masonry panels subject to lateral loadings. Comput Struct 61(4): 735-745

Lourenço PB (2008) Structural masonry analysis: recent developments and prospects. Proceedings of $14^{\text {th }}$ International Brick and Block Masonry conference. University of Newcastle. Australia

Lourenço PB (1996) Computational strategies for masonry structures. Delft University Netherlands. Available

at: http://www.hms.civil.uminho.pt/arq/fich/1996 PhD PBLourenco.pdf. Accessed 17 August 2016.

Lourenço PB, Hunegn T, Medeiros P, Peixinho N (2010) Testing and analysis of masonry arches subjected to impact loads. Proceedings of ARCH'10 6th International Conference on Arch Bridges October 2010 Fuzhou China

Marinelli A, Syrmakezis C, Antonopoulos A (2004) Structural Response of Masonry Historical Structure Using Fragility Curves. Proceedings of Third European Conference on Structural Control (3ECSC) Vienna University of Technology Vienna Austria July 2004

Martini K (1997) Finite element studies in the out-of-plane failure of unreinforced masonry. Proceedings of the Seventh International Conference on Computing in Civil and Building Engineering 1:179-84

Masonry Standards Joint Committee's (MSJC) (2008) Building Code Requirements and Specification for Masonry Structures (TMS 402/ACI 530/ASCE 5 and TMS 602/ACI 530.1/ASCE 6).

Mavrouli O, Corominas J (2010a) Vulnerability of simple reinforced concrete buildings in front of the rockfall impact. Landslides 7(2):169-180

Mavrouli O, Corominas J (2010b) Rockfall vulnerability assessment for reinforced concrete buildings. Nat Hazard Earth Syst 10:2055-2066

Mavrouli O, Fotopoulou S, Pitilakis K, Zuccaro G, Foerster E and Corominas J (2014) Analytical methodologies for the quantification of the vulnerability of buildings to landslides using fragility curves. Bull Eng Geol Environ 73:265-289

Mavrouli O, Syrmakezis C (2008) Investigation of masonry elasticity and shear moduli using finite element micro-models. Smart Struct Syst 4(2): 62-78 
Mayrhofer Chr (2002) Reinforced masonry walls under blast loading. Int J Mech Sci 44(6):10671080

Milani G, Lourenço PN. (2009) Blast analysis of enclosure masonry walls using homogenization approaches. Int J Multiscale Com 7(2-2):91-113

Mojsilovic N, Faber MH (2008) Probabilistic Model Framework for the Design of Structural Masonry, Proceedings of Inaugural International Conference of the Engineering Mechanics Institute (EM08) Minneapolis May 19-21 2008 Paper No. w805

Oliver J, Cante JC, Weyler R, González C, Hernández J (2007) Particle Finite Element Methods in Solid Mechanics Problems. In: Computational plasticity. Springer Netherlands

Oliver J, Hartmann S, Cante JC, Weyler R, Hernández JA (2009) A contact domain method for large deformation frictional contact problems. Part 1: Theoretical basis. Comput method Appl M 198(33): 2591-2606.

Oñate E, Idelsohn SR, Del Pin F, Aubry F (2004) The particle finite element method. An overview. Int J Numer Meth Eng 1(2):964-989

Papathoma-Kohle M, Neuhauser B, Ratzinger K, Wenzel H, Dominey-Howes D (2007) Elements at risk as a framework for assessing the vulnerability of communities to landslides Nat Hazard Earth Syst 7:765-779

Quan Luna B, Blahut J, van Westen C J, Sterlacchini S, van Asch T W J, Akbas S O (2011) The application of numerical debris flow modelling for the generation of physical vulnerability curves. Nat Hazard Earth Syst 11: 2047-2060

Ramakrishnan S, Lourenço PB (2009) Finite element modelling of deformation characteristics of historical stone masonry shear walls. Eng Struct 31(9): 1930-1943.

Rots JG (1991) Numerical simulation of cracking in structural masonry. Heron 36(2):49-63

Schmidt M, Cheng L (2009) Impact Response of Externally Strengthened Unreinforced Masonry Walls Using CFRP. J Compos Constr, 13(4):252-261

Syrmakezis C, Antonopoulos A, Mavrouli O (2005a) Analysis of Historical Structures using ThreeDimensional Solid Elements. Proceedings of Tenth International Conference on Civil Structural and Environmental Engineering Computing Rome Italy August 30-September 22005

Syrmakezis C, Antonopoulos A, Mavrouli O (2005b) Historical Structures Vulnerability Evaluation using Fragility Curves. Proceedings of the Tenth International Conference on Civil, Structural and Environmental Engineering Computing Rome Italy August 30-September 2, 2005

Syrmakezis C, Antonopoulos A, Mavrouli O (2007) Earthquake response and vulnerability assessment of masonry structures. Proceedings of 4th International Conference on Earthquake Geotechnical Engineering (ISSMGE) Thessaloniki Greece

Syrmakezis C, Asteris P (2001) Masonry failure criterion under biaxial stress state. J Mater Civil Eng ASCE library 13(1):58-64

Syrmakezis C, Asteris P, Antonopoulos A, Mavrouli O (2005c) Stress-Failure Analysis of Masonry Structures under Earthquake Loading. Proceedings of the Symposium on Fracture and Failure of Natural Building Stones Applications in the Restoration of Ancient Monuments 16th European 
Conference of Fracture: Failure Analysis of Nano and Engineering Materials and Structures, Alexandroupoli Greece July 3-7 2005

Totschnig R, Fuchs S (2013) Mountain torrents: Quantifying vulnerability and assessing uncertainties, Engineering Geology, 155: 31-44

Syrmakezis C, Asteris P, Antonopoulos A, Mavrouli O (2006) Use of Passive Control Systems for the Retrofitting of Masonry Arch Bridges. Proceedings of 4th World Conference on Structural Control and Monitoring San Diego California U.S.A

UNDP/UNESCO (1982) Vulnerability and Seismic Hazard. Vulnerability analysis in the Balkan Region. Project RER/79/014 WG.B Final report

Volkwein A, Schellenberg K, Labiouse V, Agliardi F, Bourrier F, Dorren LK, Gerber W, Jaboyedoff M (2011) Rockfall characterisation and structural protection - a review. Nat Hazard Earth Syst 11: $2617-2651$

Wu C, Hao H (2006) Derivation of 3D masonry properties using numerical homogenization technique. Int J Numer Method Eng 66(11): 1717-1737 